\title{
The role of the middle cerebellar peduncle in acquisition and retention of the rabbit's classically conditioned nictitating membrane response
}

\author{
PAUL R. SOLOMON, JUDITH L. LEWIS, and JOSEPH J. LOTURCO \\ Williams College, Williamstown, Massachusetts \\ and \\ JOSEPH E. STEINMETZ and RICHARD F. THOMPSON \\ Stanford University, Stanford, California
}

\begin{abstract}
In the present study, the middle cerebellar peduncles of 20 rabbits were lesioned before or after the left nictitating membrane/eyelid response was classically conditioned. Naive animals with completely destructed peduncles were unable to learn; in trained animals, the CRs were abolished using tones, lights, tactile stimulation, or pontine stimulation as conditioned stimuli. These results support the hypothesis that conditioned stimulus information is projected to the cerebellum via mossy fibers in the middle cerebellar peduncle during classical conditioning of discrete, somatic responses.
\end{abstract}

Classical conditioning of the rabbit's nictitating membrane (NM) response has become the most widely used model system for investigating neurobiological aspects of associative learning in mammals (Gormezano, Prokasy, \& Thompson, in press). There is now converging evidence from using this preparation that the cerebellum is part of an essential circuit for acquisition and retention of the conditioned NM response (McCormick \& Thompson, 1984).

If the cerebellum is the site of plasticity for NM conditioning, it becomes important to characterize the role of the cerebellar afferents and efferents in carrying information about stimuli and responses. Recent studies by Thompson and his coworkers suggest that the superior cerebellar peduncle is the primary efferent for information about the conditioned response (CR) (Lavond, McCormick, Clark, Holmes, \& Thompson, 1981; McCormick, Guyer, \& Thompson, 1982) and that the dor-

Portions of the research of Experiment 1 were supported by grants from the Sherman Fairchild Foundation and the Henry Goldman Foundation, and by a faculty research grant from Williams College to Paul R. Solomon. We are grateful to Kia Nobre and C. J. Gillig for their help in data collection and to Kate Keenan for her assistance in preparing the figures. Judith L. Lewis is now at the University of Vermont Medical College, and Joseph J. LoTurco is now at the Department of Psychology, Yale University. Portions of the research of Experiment 2 were supported by National Institute of Mental Health Fellowship No. F32MH08994 to J. E. Steinmetz, and by grants to R. F. Thompson, including NSF Grant No. BNS-8106648, Office of Naval Research Grant No. N00014-83-0238, and a Sloan Foundation grant and a McKnight Foundation grant. Reprint requests should be sent to: P. R. Solomon, Department of Psychology, Williams College, Williamstown, MA 01267. sal accessory olive-climbing fiber system, via the inferior cerebellar peduncle, is the necessary and sufficient unconditioned stimulus (US) pathway (Mauk \& Thompson, 1984; Steinmetz, McCormick, Baier, \& Thompson, 1984). Furthermore, direct electrical microstimulation of the mossy fibers of the middle cerebellar peduncle (MCP) can serve as an effective conditioned stimulus (CS) (Steinmetz, Lavond, Rosen, \& Thompson, in press; Steinmetz, Lavond, \& Thompson, 1985a, 1985b). However, it has not previously been determined whether the MCP is necessary for the CR to peripheral CSs.

The purpose of the present study was to evaluate the role of the MCP in transmitting information about conditioned stimuli. Experiment 1 evaluated the effects of MCP lesions on both acquisition and retention of the CR to CSs in three different modalities using an eye shock US. Experiment 2 attempted to replicate the retention aspect of Experiment 1 using acoustic and pontine stimulation CSs and an airpuff US.

\section{EXPERIMENT 1}

Experiment 1 (Williams College group) was designed to examine acquisition and retention of the $C R$ within the same animal (i.e., with the same amount of tissue damage). A second purpose of this experiment was to evaluate the effects of MCP lesions on CR acquisition and retention using auditory, visual, and tactile conditioned stimuli.

\section{Method \\ Subjects. The animals were 18 experimentally naive New Zealand albino rabbits (Oryctolagus cuniculus), weighing between 2 and $4 \mathrm{~kg}$}


at the time of surgery. All rabbits were individually housed in a temperature- and humidity-controlled colony with a 12 -h light/12-h dark cycle. Animals were tested during the light portion of the cycle.

Surgery. Animals were anesthetized with Fluothane (halothane) gas mixture and then injected subcutaneously with Xylocaine (lidocaine $\mathrm{HCl}$ ) along the midline of the scalp. Placement of the lesion electrode was accomplished via a combination of stereotaxic and electrophysiological techniques. Initial electrode placements were made at $3.3 \mathrm{~mm}$ anterior to lambda and $6.8 \mathrm{~mm}$ lateral to the midline (with lambda $1.5 \mathrm{~mm}$ ventral to bregma). The dorsal-ventral coordinate was determined by characteristic neuronal activity. Lesions were made via radio-frequency current (Radionics Model RFG-4A), which produced a tip temperature of $70^{\circ}$ for $1 \mathrm{~min}$ through a $0.25-\mathrm{mm}$ diameter electrode that was insulated except for $1 \mathrm{~mm}$ at the tip. Two lesions were made in each MCP, and animals were given a minimum of 5 days to recover between surgery and behavioral testing.

Apparatus. The apparatus for conditioning the rabbits' NM has been described in detail (Solomon, 1977). Briefly, 4 animals were run simultaneously in sound-attenuated and ventilated chambers. A panel in front of each chamber contained two lights, each mounted behind a translucent milk-white screen, used to deliver the visual CS, and a speaker used to deliver the auditory (tone) CS. The tactile (vibratory) CS was delivered via a speaker mounted on the animal's back.

Each rabbit was restrained in a Plexiglas box. A small nylon loop was sutured through the animal's right NM and attached to the shaft of a rotary transducer. In this way, lateral movement of the NM was transduced into a direct current signal.

The CSs in this experiment were an 85-dB tone, a 6-V light, and a vibratory stimulus consisting of 5- $\mathrm{Hz}$ stimulation to the animal's shaved back. We had previously determined that this stimulus had no auditory signaling properties: it would not produce conditioning when the speaker was moved 1 in. above the animal's back.

The CS duration was $500 \mathrm{msec}$, and the time between CS onset and US onset was $450 \mathrm{msec}$. The US was a $2-\mathrm{mA}$ infraorbital shock of 50msec duration delivered via two stainless steel wound clips implanted superficially in the skin, one immediately below and the other immediately posterior to the shaved right eye. The intertrial interval was a constant $30 \mathrm{sec}$.

Behavioral testing. On the day following suturing of the NM, the rabbits were restrained and placed in the conditioning apparatus for $1 \mathrm{~h}$. On the next day, half the animals received paired presentations of the tone CS and eye shock US, and half the animals received paired presentations of the light CS and shock. Each animal received 100 CS-US presentations per day until it reached a criterion of 1 day of $80 \%$ or more CRs. The animal was then given 1 additional day of training. Animals then received bilateral lesions of the MCP or served as unoperated controls (CON). Following surgery, all animals received individual presentations of three stimuli (tone, light, vibratory), paired with the US until the rabbits reached a criterion of $70 \%$ or more CRs to each of the three stimuli or for a maximum of 25 days. Each CS was paired with the US 36 times per day. In this way, it was possible to measure both acquisition and retention of the $C R$ within the same animals. In each case, conditioning to the previously trained light or tone served as the retention test, whereas conditioning to the remaining two conditioned stimuli (tone and vibratory or light and vibratory) served as a test of acquisition.

\section{Results}

At the completion of behavioral testing, animals were sacrificed, and their brains were subjected to histological analysis. Animals were divided into three conditions on the basis of histological findings: (1) misses (MISS) no damage to the MCP, (2) partial (PAR)-partial damage to the MCP, and (3) complete (COM)-bilateral interruption to the MCP. Figure 1 shows a representative reconstruction from 1 animal in each condition.

Acquisition of the conditioned response. Because animals with damage to areas other than the MCP (Group MISS) and unoperated controls (Group CON)

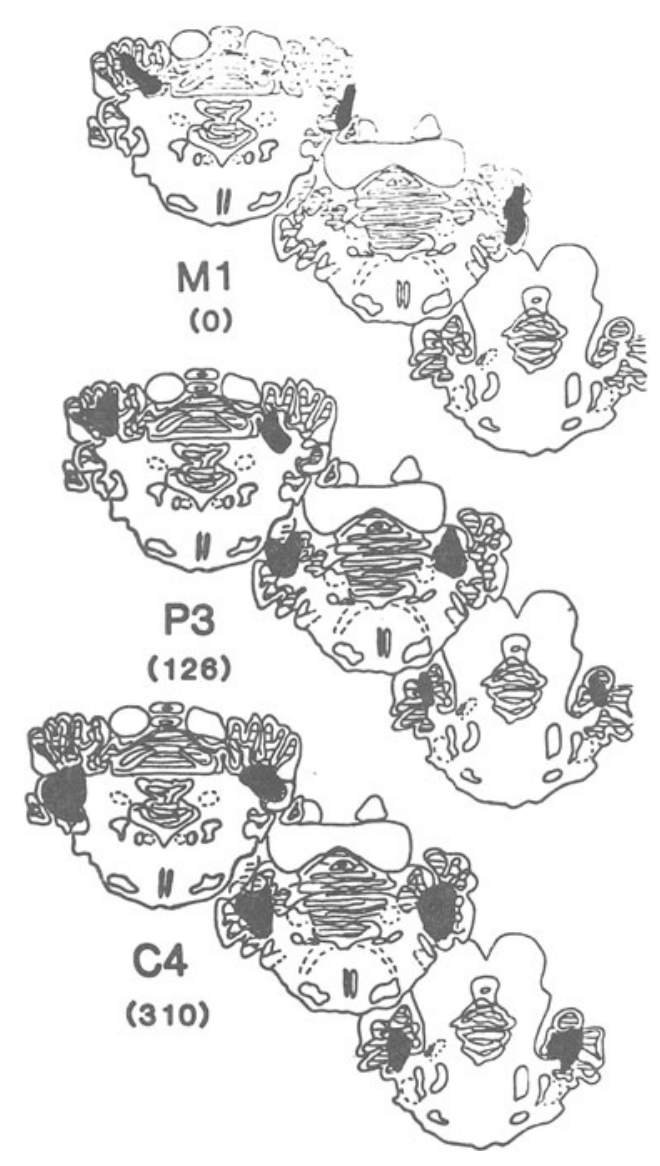

Figure 1. Representative reconstructions of MCP lesions from Experiment 1. Animal M1 is a rabbit with no MCP damage. Animal P3 is an animal with partial MCP damage and Animal C4 is an example of a complete MCP lesion. Numbers in parentheses are digitized estimates of bilateral MCP damage summed across all three coronal sections.

were indistinguishable in terms of their behavioral performance, their data were combined for statistical analyses. The dependent measure in these analyses was the mean total number of CRs to each stimulus out of a possible 360 (36 trials per day for each stimulus for the 10 days that all animals were run). For each of the tone, light, and vibratory CSs, animals in Group MISS + CON acquired the conditioned response significantly faster than animals in Group PAR, who acquired the CR significantly faster than animals in Group COM $(U s=0, p<.02)$. Moreover, there was no overlap in the range of trials to criterion between Groups MISS + CON, PAR, and COM for any of the three stimuli (Table 1).

Retention of the conditioned response. As in the case of the acquisition data, data from animals in Groups MISS and CON were combined for statistical analysis. The dependent measure was the number of CRs out of a possible 360. For both tone and light CSs, animals in Group MISS + CON emitted significantly more CRs during retention testing than did animals in Group PAR, who emitted significantly more CRs than animals in Group COM $(U s=0, p<.02)$. Again there was no 
Table 1

Range of Total CRs (360 Possible) to Each of the Three Stimuli for Animals in the Three Surgical Treatment Conditions

\begin{tabular}{lccc}
\hline Stimulus & Treatment & Acquisition & Retention \\
\hline \multirow{4}{*}{ Tone } & MISS + CON & $281-329$ & $311-340$ \\
& PAR & $107-267$ & $32-82$ \\
& COM & $4-9$ & $3-15$ \\
Light & MISS + CON & $147-217$ & $217-348$ \\
& PAR & $48-72$ & $44-222$ \\
& COM & $13-19$ & $4-9$ \\
Vibratory & MISS + CON & $148-308$ & \\
& PAR & $22-118$ & \\
& COM & $3-18$ & \\
\hline
\end{tabular}

overlap in the range of distributions between the three surgical groups for either stimulus (Table 1).

These data indicate that large bilateral lesions of the MCP severely disrupt retention of the classically conditioned NMR to both a tone and light CS, and acquisition of the CR to a tone, light, and tactile CS. Both acquisition and retention were also disrupted, but to a lesser degree, in animals with partial MCP lesions.

\section{EXPERIMENT 2}

Experiment 2 (Stanford University group) was planned to replicate the Williams College group's findings on retention of the $\mathrm{CR}$, using the standard conditions of the Stanford laboratory, which differ in several ways from those at Williams College, and using electrical microstimulation of the dorsolateral pontine nucleus (cells of origin of mossy fibers projecting to the cerebellum via the MCP) as well as tone CSs.

\section{Method}

Two male albino rabbits were used in this experiment. The rabbits were given food and water ad lib, individually housed, and placed on 12-h light/12-h dark cycles. All experimental procedures were carried out during light portions of the light/dark cycle.

While under halothane anesthesia $(2 \%-3 \%)$, the rabbits were first implanted with bipolar, stainless steel stimulating electrodes in the right dorsolateral pontine nucleus (DLPN) and with stainless steel lesion electrodes in the right and left MCP. The stimulating electrodes had 200$\mu \mathrm{m}$ exposed tips and were placed $10.5 \mathrm{~mm}$ posterior to bregma, 2.5 and $3.5 \mathrm{~mm}$ medial to midline, and $20.0 \mathrm{~mm}$ below bregma. Lesion electrodes had $500-\mu \mathrm{m}$ exposed tips and were implanted $3.0 \mathrm{~mm}$ anterior to lambda, $6.5 \mathrm{~mm}$ lateral to the midline, and $14.5-15.5 \mathrm{~mm}$ below lambda. Electrodes were positioned with lambda $1.5 \mathrm{~mm}$ ventral to bregma using a combination of stereotaxic and electrophysiological techniques. The rabbits were allowed 1 week for recovery after surgery.

Initially, the animals were placed in a standard restraint box and allowed $1 \mathrm{~h}$ to adapt to the sound-attenuated conditioning chamber. On the next day, classical eyelid conditioning sessions were begun. Each daily conditioning session was composed of 108 trials ( 12 blocks of 9 trials with each block containing one CS-alone presentation and eight paired CS-US presentations) with an average intertrial interval of $30 \mathrm{sec}$. Rabbits were first trained to a conditioning criterion (eight conditioned eyelid responses on 9 consecutive trials) and overtrained with daily training sessions using stimulation of the DLPN as the CS and airpuff as the US. For this phase of training, the CS was a 350-msec train of bipolar brain stimulation $(60-\mu \mathrm{A}, 200-\mathrm{Hz}, 0.1-\mathrm{msec}$ pulses) that coterminated with a $100-\mathrm{msec}$ airpuff $\left(2.1 \mathrm{~N} / \mathrm{cm}^{2}\right)$ directed at the cornea of the left eye. Movements of the NM were monitored by a minitorque potentiometer via a suture placed in the NM during surgery. Membrane exten- sion of $.5 \mathrm{~mm}$ or more that occurred after CS onset but before US onset were classified as CRs. After training with the DLPN stimulation CS, the rabbits were trained to the conditioning criterion with a tone CS and airpuff US, and then overtrained with an additional session. During this phase of conditioning, the CS was a $350-\mathrm{msec}$ tone $(1-\mathrm{kHz}$, 85-dB SPL sine wave) that coterminated with a 100 -msec airpuff directed at the left cornea. Finally, on the last day of training, the rabbits were given six blocks of DLPN stimulation and six blocks of tone training.

After initial stimulation and tone training, the rabbits were lightly anesthetized with halothane and given bilateral electrolytic lesions of the MCP by passing 2-mA dc for $1 \mathrm{~min}$. Twenty-four hours after the lesion, paired CS-US training was reinstated for eight daily sessions. On Days 1, 2, 5, and 6, DLPN stimulation was used as the CS, whereas on Days $3,4,7$, and 8 , presentations of the tone served as the CS. Following the last day of postlesion training, the rabbits were sacrificed with an overdose of sodium pentobarbital, perfused via the aorta with saline followed by $10 \%$ formalin, and the stimulating sites were marked by passing $200-\mu \mathrm{A} \mathrm{dc}$ for $10 \mathrm{sec}$. The brains were then removed, embedded, sliced on a microtome, and stained with cresyl violet for cell bodies and potassium ferrocyanide for iron deposits left by the lesions.

\section{Results}

Training with the DLPN stimulation CS and airpuff US produced rapid eyelid conditioning in the 2 rabbits with an average conditioned response amplitude of $3.7 \mathrm{~mm}$ recorded during the overtraining session. Likewise, robust eyelid conditioning was obtained when the tone CS was paired with the airpuff US. The average conditioned response amplitude was $2.4 \mathrm{~mm}$ during overtraining with the tone CS. Lesions of the MCP, however, produced an immediate and permanent abolition of the CRs previously established with both the DLPN stimulation and tone CSs. The average conditioned response amplitudes recorded on the last postlesion days of training were $0.1 \mathrm{~mm}$ with the stimulation CS and $0.1 \mathrm{~mm}$ with the tone CS. The amplitudes of the unconditioned responses were not affected by the MCP lesions.

Examination of CS stimulation sites revealed electrode placements in the right DLPN. In addition, examination of the peduncle lesions revealed destruction of medial portions of the left MCP in 1 animal (see Figure 2) and destruction of the central portion of the left MCP with slight damage to overlying cerebellar cortex in the other animal. Only slight damage to the right MCP was observed in the 2 rabbits, suggesting that at the level of the cerebellum, only the MCP ipsilateral to the trained eye is essential. The lesions caused no detectable damage to the interpositus nucleus or to the superior or inferior cerebellar peduncles.

\section{GENERAL DISCUSSION}

The present experiments show that sufficiently large lesions of the MCP prevent acquisition and immediately abolish retention of the NM CR. Given the fact that the MCP contains the great majority of afferents to the cerebellum, in the form of mossy fibers, these results suggest that the MCP is the essential CS channel to the cerebellar memory trace system. Since electrical microstimulation of the MCP (directly or via the pontine nuclei; Steinmetz et al., 1985a, 1985b; also see Experiment 2 above) is an effective CS, yielding normal behavioral CRs, these results collectively suggest that mossy fibers of the MCP form a portion of the necessary and sufficient CS pathways for classical conditioning of discrete, adaptive behavioral CRs. If so, it appears that at the level of the cerebellum, only fibers of the MCP ipsilateral to the trained eye may carry essential CS information. 

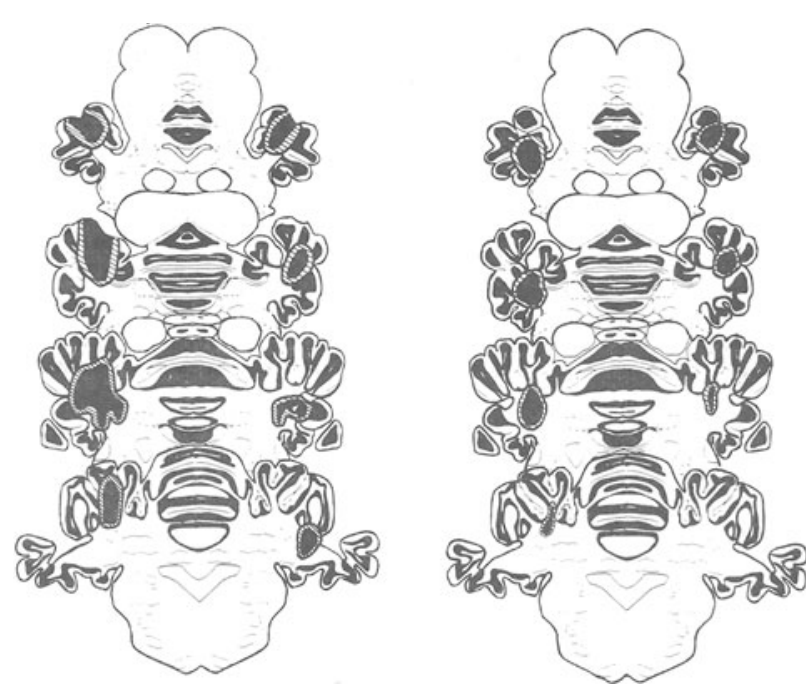

Figure 2. Schematic drawings of middle cerebellar peduncle lesions for the 2 rabbits used in Experiment 2 (shaded areas surrounded by striped border). From top to bottom, the drawings represent coronal sections located $4,3,2$, and $1 \mathrm{~mm}$ anterior to the lambda suture line.

Identification of the essential CS pathways has been the one major component of the essential CR circuit not previously determined. The essential efferent CR pathway consists of fibers exiting from the interpositus nucleus ipsilateral to the trained side of the body in the superior cerebellar peduncle, crossing to relay in the contralateral magnacellular division of the red nucleus and crossing back to descend in the rubral pathway to act ultimately on motor neurons (Chapman, Steinmetz, \& Thompson, 1985; Haley, Lavond, \& Thompson, 1983; Lavond et al., 1981; Madden, Haley, Barchas, \& Thompson, 1983; McCormick \& Thompson, 1984; McCormick et al., 1982; Rosenfield, Devydaitis, \& Moore, 1985; Rosenfield \& Moore, 1983).

Two lines of evidence argue strongly that the essential US pathway, the necessary and sufficient pathway conveying information about the US to the cerebellar memory trace circuit, consists of climbing fibers from the dorsal accessory olive (DAO) projecting via the inferior cerebellar peduncle: (1) Lesion of the appropriate region of the DAO prevents acquisition and produces normal extinction of the behavioral NM CR with continued paired training in already trained animals (McCormick, Steinmetz, \& Thompson, 1985; Steinmetz et al., 1984), and (2) electrical microstimulation of this same region of the DAO serves as an effective US for learning of the normal behavioral NM CR (Mauk \& Thompson, 1984; Steinmetz, Lavond, \& Thompson, 1985b).

Collectively, these results suggest an essential cerebellar memory trace circuitry of elegant simplicity, in close accord with the known anatomy of the system (Brodal, 1981) and with earlier theories suggesting critical involvement of the cerebellum in acquisition and retention of motor skills (e.g., Albus, 1971; Eccles, 1977; Ito, 1968; Marr, 1969), namely that the essential US reinforcing or "teaching" input is via climbing fibers in the inferior cerebellar peduncle, the essential CS "learning" input is via mossy fibers in the MCP and the essential efferent CR pathway is via fibers in the superior cerebellar peduncle. The two major remaining unknowns are the exact pathways conveying CS information from primary sensory systems to mossy fibers and the exact location(s) of the memory traces themselves in the cerebellum.

\section{REFERENCES}

Albus, J. S. (1971). A theory of cerebellar function. Mathematical Bioscience, 10, 26-61.

Brodal, A. (1981). Neurological anatomy in relation to clinical medicine. New York: Oxford University Press.
Chapman, P. F., Steinmetz, J. E., \& Thompson, R. F. (1985). Classical conditioning of the rabbit eyeblink does not occur with stimulation of the cerebellar nuclei as the unconditioned stimulus. Neuroscience Abstracts, 11, 835.

EcCLEs, J. C. (1977). An instruction selection theory of learning in the cerebellar cortex. Brain Research, 127, 327-352.

Gormezano, I., Prokasy, W. F., \& Thompson, R. F. (in press). Classical conditioning III: Behavioral, neurophysiological, and neurochemical studies in the rabbit. Hillsdale, NJ: Erlbaum.

Haley, D. A., Lavond, D. G., \& Thompson, R. F. (1983). Effects of contralateral red nuclear lesions on retention of the classically conditioned nictitating membrane/eyelid response. Neuroscience Abstracts, 9, 643.

ITo, M. (1968). Neurophysiological aspects of the cerebellar motor control system. International Journal of Neurology, 7, 162-176.

Lavond, D. G., McCormick, D. A., Clark, G. A., Holmes, D. A., \& THOMPSON, R. F. (1981). Effects of ipsilateral rostral pontine reticular lesions on retention of classically conditioned rabbit nictitating membrane responses. Physiological Psychology, 9, 335-339.

Madden, J., Haley, D. A., Barchas, J. D., \& Thompson, R. F. (1983). Microinfusion of picrotoxin into the caudal red nucleus selectively abolishes the classically conditioned eyelid response in the rabbit. Neuroscience Abstracts, 9, 830.

MARR, D. A. (1969). A theory of cerebellar cortex. Journal of Physiology (London), 202, 437-470.

Mauk, M. D., \& Thompson, R. F. (1984). Classical conditioning using stimulation of the inferior olive as the unconditioned stimulus. Neuroscience Abstracts, 10, 122.

McCormick, D. A., Guyer, P. E., \& Thompson, R. F. (1982). Superior cerebellar peduncle lesions abolish the ipsilateral classically conditioned nictitating membrane/eyelid response of the rabbit. Brain Research, 245, 347-350.

McCormick, D. A., Steinmetz, J. E., \& Thompson, R. F. (1985). Lesions of the olivary complex cause extinction of the classically conditoned eyelid response. Brain Research, 359, 120-130.

McCormick, D. A., \& Thompson, R. F. (1984). Neuronal responses of the rabbit cerebellum during acquisition and performance of a classically conditioned nictitating membrane/eyelid response. Journal of Neuroscience, 4, 2811-2822.

Rosenfield, M. E., Devydaitis, A., \& MoORE, J. W. (1985). Brachium conjunctivum and rubrobulbar tract: Brainstem projections of red nucleus essential for the conditioned nictitating membrane response. Physiology \& Behavior, 34, 751-759.

Rosenfield, M. E., \& Moore, J. W. (1983). Red nucleus lesions disrupt the classically conditioned nictitating membrane response in the rabbit. Behavioral Brain Research, 10, 393-398.

Solomon, P. R. (1977). Role of the hippocampus in blocking and conditioned inhibition of the rabbit's nictitating membrane response. Journal of Comparative \& Physiological Psychology, 91, 407-417.

Steinmetz, J. E., Lavond, D. G., Rosen, D. J., \& Thompson, R. F. (in press). Classical conditioning of the rabbit eyelid response with a mossy fiber stimulaton CS: I. Pontine nuclei send middle cerebellar peduncle stimulation. Behavioral Neuroscience.

SteinmeTz, J. E., LAvond, D. G., \& THOMPSON, R. F. (1985a). Classical conditioning of the rabbit eyelid response with mossy fiber stimulation as the conditioned stimulus. Bulletin of the Psychonomic Society, 23, 245-248.

Steinmetz, J. E., Lavond, D. G., \& Thompson, R. F. (1985b). Classical conditioning of skeletal muscle responses with mossy fiber stimulation CS and climbing fiber stimulation US. Neuroscience Abstracts, 11, 982.

Steinmetz, J. E., McCormick, D. A., Baier, C. A., \& Thompson, R. F. (1984). Involvement of the inferior olive in classical conditioning of the rabbit eyelid. Neuroscience Abstracts, 10, 122.

(Manuscript received for publication December 9, 1985.) 